Revista Perspectivas Online: Exatas \& Engenharia Outubro/2021, v.11, n.33, p.19-33 ISSN: 2236-885X (Online)

DOI: $10.25242 / 885 X 113320212353$

\title{
ACIDENTES DO TRABALHO E CULTURA DE SEGURANÇA NO SETOR DA CONSTRUÇÃO CIVIL
}

\author{
Nathália de Faria Borges', Isabela Pessanha Vilaça ${ }^{I}$ \& Quézia Manuela Gonçalves \\ Laurindo $^{1}$
}

\begin{abstract}
RESUMO
BORGES, N. F.; VILAÇA, I. P.; LAURINDO, Q. M. G.SILVA, F.; SILVA, B. Acidentes do trabalho e cultura de segurança no setor da construção civil. Perspectivas Online: Exatas \& Engenharia, v.11, n.33, p.19-33, 2021.

A construção civil é uma das atividade econômicas mais importantes do país. No entanto, o número de acidentes do trabalho que ocorrem nesta indústria é expressivo. Diante desse cenário, o objetivo deste trabalho consiste em trazer uma abordagem dos principais temas referentes à segurança do trabalho em canteiros de obras da construção civil, identificando as características deste setor que contribuem para $\mathrm{o}$ alto índice de acidentes, e apresentando as normas regulamentadoras e a cultura de segurança como fatores importantes para a promoção da saúde e

segurança no ambiente laboral. Para isso, foi utilizada como metodologia a busca de dados quantitativos na Câmara Brasileira da Indústria da Construção (CBIC) e no Observatório de Segurança e Saúde no Trabalho, além da busca de artigos na base SCOPUS Elsevier. Os dados coletados nas referidas fontes contribuíram para identificar que a maioria das empresas de construção civil no Brasil não atende às normas regulamentadoras, fator que, juntamente com a não existência de investimentos em segurança, contribui para $o$ alto índice de acidentes nesse setor.
\end{abstract}

Palavras-chave: Segurança do trabalho; Construção Civil; Acidentes.

\footnotetext{
${ }^{1}$ Universidade Candido Mendes - Av. Anita Pessanha, 100, Parque São Caetano, Campos dos Goytacazes, RJ, CEP: 28030-335, Brasil.

(*) e-mail: nathalia.fariaborges@gmail.com

Data de recebimento:22/07/2021 Aceito para publicação: 29/09/2021

. Data de publicação: 23/10/2021
} 
Revista Perspectivas Online: Exatas \& Engenharia October/2021, v.11, n.33, p. ISSN: 2236-885X (Online)

DOI: $10.25242 / 885 X 113320212353$

\title{
OCCUPATIONAL ACCIDENTS AND SAFETY CULTURE IN THE CIVIL CONSTRUCTION SECTOR
}

\author{
Nathália de Faria Borges', Isabela Pessanha Vilaça ${ }^{I}$ \& Quézia Manuela Gonçalves \\ Laurindo $^{1}$
}

\begin{abstract}
BORGES, N. F.; VILAÇA, I. P.; LAURINDO, Q. M. G.SILVA, F.; SILVA, B. Acidentes do trabalho e cultura de segurança no setor da construção civil. Perspectivas Online: Exatas \& Engenharia, v.11, n.33, p.19-33, 2021
\end{abstract}

Civil construction is one of the most important economic activities in the country. However, the number of work accidents that occur in this industry is expressive. In view of this scenario, the objective of this work is to approach the main themes related to work safety in civil construction sites, identifying the characteristics of this sector that contribute to the high rate of accidents, and presenting the regulatory standards and the safety culture as important factors for promoting health and safety in the workplace. For this, the methodology used was based on the search for quantitative data at the Brazilian Chamber of Construction Industry (CBIC) and at the Occupational Health and Safety Observatory, in addition to the search for articles in the SCOPUS Elsevier database. The data collected from these sources helped to identify that most civil construction companies in Brazil do not meet regulatory standards, a factor that, together with the non-existence of investments in safety, contributes to the high rate of accidents in this sector.

Keywords: Work Safety; Civil Construction; Accidents.

${ }^{1}$ Candido Mendes University -Anita Pessanha Avenue, 100, Parque São Caetano, Campos dos Goytacazes, RJ, Postal Code: 28030-335, Brazil

(*) e-mail: nathalia.fariaborges@gmail.com

Received: $22 / 07 / 2021$ 


\section{PERSPECTIVAS online}

\section{INTRODUÇÃO}

A construção civil é uma das atividades mais antigas do mundo. Desde os primórdios da humanidade, o homem engenha abrigos e ferramentas para sua sobrevivência (WELTER, 2014). Também é uma das mais importantes atividades econômicas do Brasil, por ser responsável pela geração de múltiplos empregos e de renda (GIZONI e MARCO, 2018).

Embora seja um dos setores mais antigos, conforme Gonçalves (2018), o setor da construção civil é o que menos se desenvolve tecnologicamente no Brasil e o que mais provoca acidentes fatais. Segundo Welter (2014) e Sampaio (2020), uma série de fatores comprometem o desempenho desse setor, dos quais podem ser citados: alto índice de desperdício, condições precárias de trabalho, alta rotatividade dos trabalhadores, uso extensivo de mão de obra terceirizada, falta de tradição de elaboração de projetos de segurança, métodos arcaicos de trabalho devido ao pouco investimento em tecnologia, elevados índices de acidentes, dentre outros aspectos.

Além disso, as construtoras, visando reduzir o custo do trabalho e maximizar a eficácia produtiva nos canteiros de obras, implantam medidas de descentralização de um número crescente de tarefas, em condições precárias e menos protegidas. Com isso, estabelece-se um segundo mercado de trabalho, sem direitos trabalhistas e previdenciários, em que os riscos de acidentes de trabalho e doenças profissionais são potencializados (OLIVEIRA E IRIART, 2008).

Outro fator que contribui negativamente para a saúde e segurança dos trabalhadores é o negligenciamento das normas regulamentadoras (NRs) pelas organizações (FILGUEIRAS, 2015). Embora sejam de observância obrigatória pelas empresas privadas e públicas e pelos órgãos públicos da administração direta e indireta, bem como pelos órgãos dos Poderes Legislativo e Judiciário que possuam empregados regidos pela Consolidação das Leis do Trabalho (CLT), há falhas na imposição das normas e fiscalização das mesmas, no sentido de responsabilizar os infratores (GONÇALVES, 2018).

Embora exista legislação a respeito da saúde e segurança do trabalho, há um limitado interesse das empresas em conhecer, de forma aprofundada, a NR-18 (Condições de Segurança e Saúde no Trabalho na Indústria da Construção), bem como outras normas regulamentadoras pertinentes à indústria da construção, como a NR-6 (Equipamentos de Proteção Individual), a NR-8 (Edificações), a NR-12 (Segurança no Trabalho em Máquinas e Equipamentos), a NR-26 (Sinalização de Segurança) e a NR-35 (Trabalho em Altura), dentre outras.

O baixo interesse em conhecer e aplicar as normas de saúde e segurança do trabalho, por parte das empresas, demonstra a falta de uma cultura organizacional voltada para a segurança. O nível de desconhecimento e despreparo dos profissionais atuantes nos níveis gerenciais (engenheiros, arquitetos, dentre outros), com relação à segurança do trabalho, dificulta a criação de uma cultura de segurança entre os funcionários do canteiro de obras (PEINADO, 2019).

A cultura de segurança, de acordo com Gonçalves Filho et al. (2011), "depende de três aspectos: aspecto relativo ao indivíduo, que inclui crenças e valores do indivíduo; aspecto relativo ao trabalho, que inclui gestão de risco, e aspecto relativo à organização, que inclui suporte ao indivíduo e à gestão". Sendo assim, quanto maior o grau de maturidade da cultura 
de segurança de uma empresa, menor será o índice de acidentes. Por esse grau de maturidade também é possível identificar quais áreas da empresa necessitam de melhorias e de investimentos (CASAGRANDE, 2017).

Frente ao que foi exposto, evidencia-se a existência de diversas barreiras à devida atuação da saúde e segurança do trabalho no setor de construção civil, e a necessidade de tornar esse tema valorizado nas empresas, para que haja perspectiva de mudança do cenário atual. Portanto, o presente artigo tem como objetivo principal identificar fatores que contribuem para a negligência da segurança do trabalho no setor da construção civil no Brasil, bem como apresentar iniciativas que poderiam contribuir para a redução dos índices de acidentes neste setor.

\section{METODOLOGIA}

No presente estudo, a busca por dados quantitativos para embasar as discussões foram coletados da Câmara Brasileira da Indústria da Construção (CBIC) e do Observatório de Segurança e Saúde no Trabalho, o SmartLab, que é um laboratório multidisciplinar de gestão do conhecimento com foco na promoção do trabalho adequado no Brasil, instituído pelo Ministério Público do Trabalho (MPT) e pela Organização Internacional do Trabalho (OIT).

Além disso, a plataforma de busca de artigos científicos SCOPUS Elsevier foi utilizada para fomentar o embasamento teórico do presente estudo. A escolha da SCOPUS Elsevier como plataforma de busca de documentos se deve à sua representatividade e abrangência, sendo a mesma usada por mais de 5.000 instituições acadêmicas, governamentais e corporativas, incluindo organizações de topo (SCOPUS Elsevier, 2021).

A metodologia de busca de artigos científicos utilizada no presente estudo é apresentada na Figura 1, incluindo a escolha das palavras-chave mais pertinentes ao tema de pesquisa, a busca de documentos na base selecionada e, por fim, a filtragem e coleta dos documentos mais pertinentes.

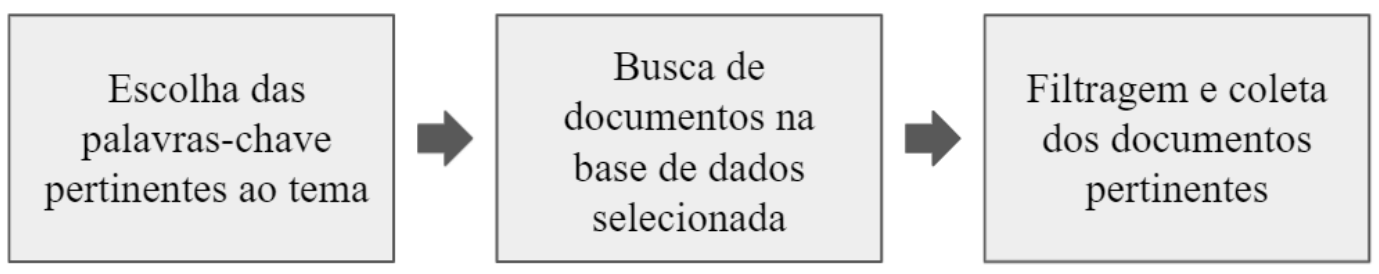

Figura 1: Metodologia de busca de documentos. Fonte: Autores (2021)

As palavras-chave escolhidas para a busca de documentos na base de pesquisa SCOPUS Elsevier, correspondem à: segurança do trabalho; construção civil; indústria da construção; canteiros de obras; NR-18. Na Tabela 1 são apresentados resultados das buscas realizadas na plataforma SCOPUS ultilizando as palavras-chave escolhidas. Os parâmetros de busca abrangeram documentos: de todos os anos disponíveis na base; todos os idiomas; todos os tipos de documentos; todas as áreas de conhecimento. 
Tabela 1: Resultados da busca de documentos na plataforma de dados. Fonte: SCOPUS Elsevier (2021)

\begin{tabular}{c|c}
\hline Palavras-chave & $\begin{array}{c}\text { Número de } \\
\text { documentos }\end{array}$ \\
\hline $\begin{array}{c}\text { Segurança do trabalho } \\
\text { Segurança do trabalho AND construção civil OR indústria da } \\
\text { construção }\end{array}$ & 9.258 \\
Segurança do trabalho AND canteiro de obras \\
Construção civil AND NR-18 & 1.353 \\
\hline
\end{tabular}

Conforme evidenciado na Tabela 1 , dos 9.258 documentos relacionados a segurança do trabalho, apenas 1.353 tratam sobre o setor de construção civil, e 968 têm como foco o canteiro de obras. Além disso, na busca, foram encontrados 9 trabalhos que citam a norma regulamentadora NR-18.

Com o propósito de evidenciar a importância da discussão sobre segurança do trabalho na construção civil a nível mundial, foi elaborado um gráfico adotando o número de publicações sobre tal tema nos últimos 20 anos, mostrado a Figura 2.

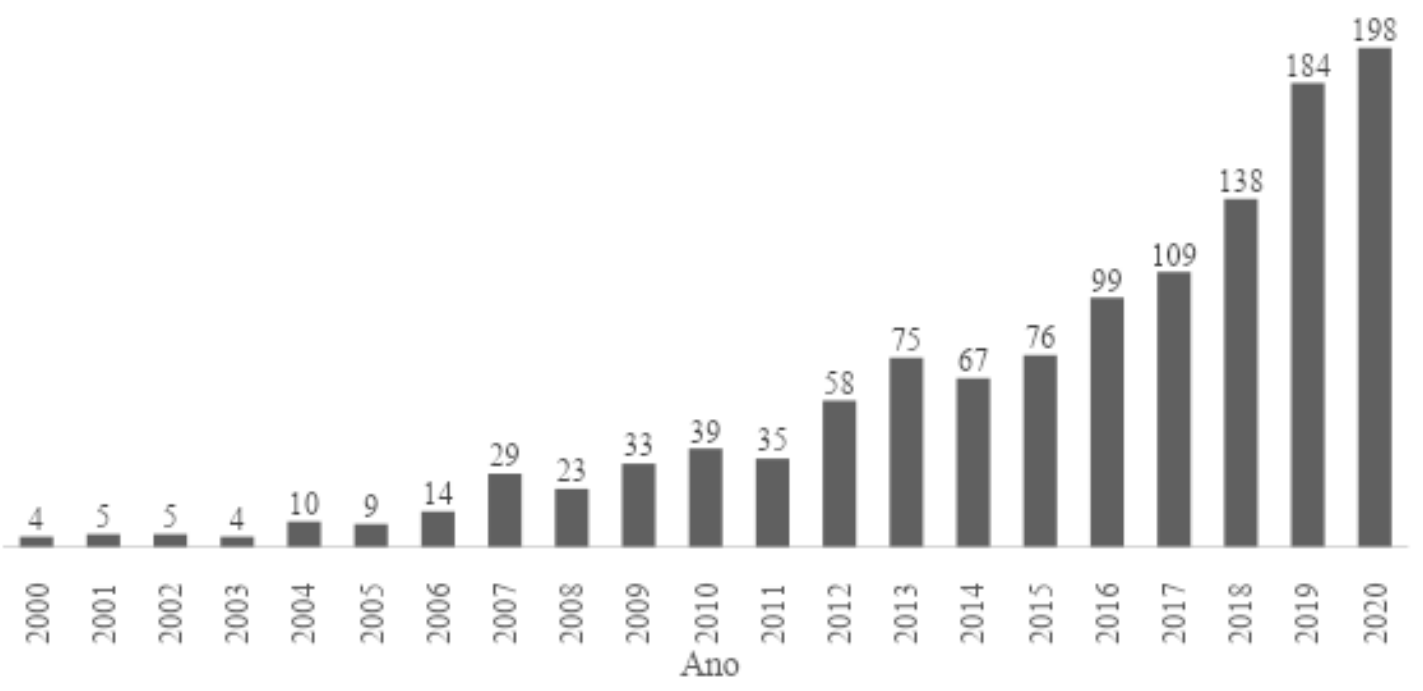

Figura 2: Número de documentos por ano de publicação. Fonte: SCOPUS Elsevier (2021)

Conforme evidenciado na Figura 2, houve um aumento expressivo nas publicações sobre segurança do trabalho na construção civil nos últimos 20 anos, evidenciando o interesse crescente em debater o tema e propor melhorias. 


\section{RESULTADOS E DISCUSSÃO}

a. Informalidade e taxa de rotatividade no setor da construção civil

No ano de 2020, a construção civil foi responsável por 7,31\% das pessoas ocupadas no país, ou seja, 6,86 milhões de um total de 93,8 milhões de trabalhadores. A informalidade alcança 34,99 milhões de pessoas no Brasil, sendo que 4,33 milhões estão no setor da construção civil (CBIC, 2020). A Figura 3 apresenta esses dados.

Com base nos dados apresentados na Figura 3, observa-se que a maioria dos trabalhadores da construção civil são informais (correspondente a 63\% do total), enquanto no mercado de trabalho do país como um todo, a informalidade é menor (correspondente a 37\% do total), dados que evidenciam a relação inversa entre a informalidade no setor da construção civil e no mercado de trabalho nacional (CBIC, 2020).

Essa estatística é preocupante, uma vez que as condições de trabalho na informalidade são, geralmente, mais perigosas. Isto de deve, sobretudo, à ausência de proteção legal assegurada pela informalização do contrato de trabalho, que, aliado à falta de fiscalização, contribuem para a negligência da segurança no trabalho e consequente aumento do número de acidentes (MENDES e CAMPOS, 2004).

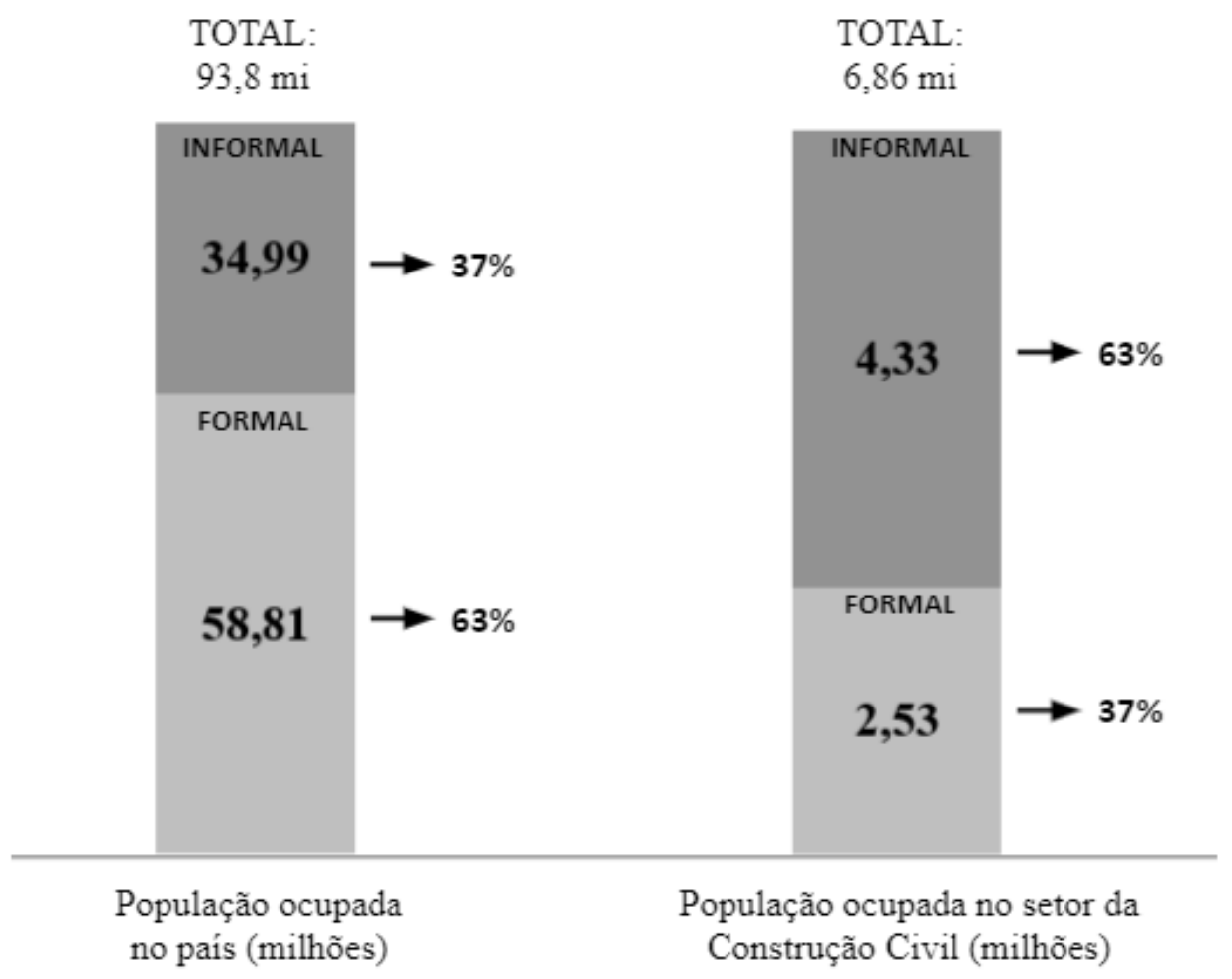

Figura 3: Trabalhadores formais e informais no país e no setor da construção civil.

(Fonte: adaptado de CBIC, 2020)

Outro fator característico do setor da construção civil, e que influencia negativamente na segurança do trabalho, é a alta taxa de rotatividade. Em um levantamento do Ministério da 
Economia, em uma escala de 0 a 10 (sendo 10 o maior nível da taxa de rotatividade), a construção civil possui um nível de 4,9, sendo a média geral nacional de 3,8. Nesse cenário, o setor da construção civil é o terceiro maior em rotatividade de colaboradores no país. Esse alto índice do chamado turnover - fluxo de entradas e saídas de funcionários em uma empresa - pode contribuir também para uma baixa produtividade, falta de qualidade, atrasos e prejuízos em projetos de construção civil (CELERE, 2019).

b. Acidentes do trabalho em setores da economia com enfoque na construção civil

De acordo com dados do Observatório Digital de Segurança e Saúde do Trabalho (2021), o setor da construção civil, mais especificamente a construção de edifícios, é o quinto setor com maior índice de acidentes do trabalho dentre os mais de 600 setores econômicos analisados, ficando atrás apenas dos setores de transporte rodoviário de cargas, administração pública em geral, comércio varejista e atividades de atendimento hospitalar (Figura 4).

Estando entre os setores com maiores índices de acidentes no Brasil, fica evidente a negligência na segurança do trabalho nas construções de edifícios. Cabe ainda ressaltar que, em muitos casos, não há a emissão da Comunicação de Acidente do Trabalho (CAT). De acordo com dados do Observatório de Segurança e Saúde do Trabalho (2021), no ano de 2018, aproximadamente $24,7 \%$ dos acidentes de trabalho de todos os setores econômicos do Brasil foram subnotificados, logo, o número real de acidentes ocorridos é maior do que o contabilizado nas pesquisas.

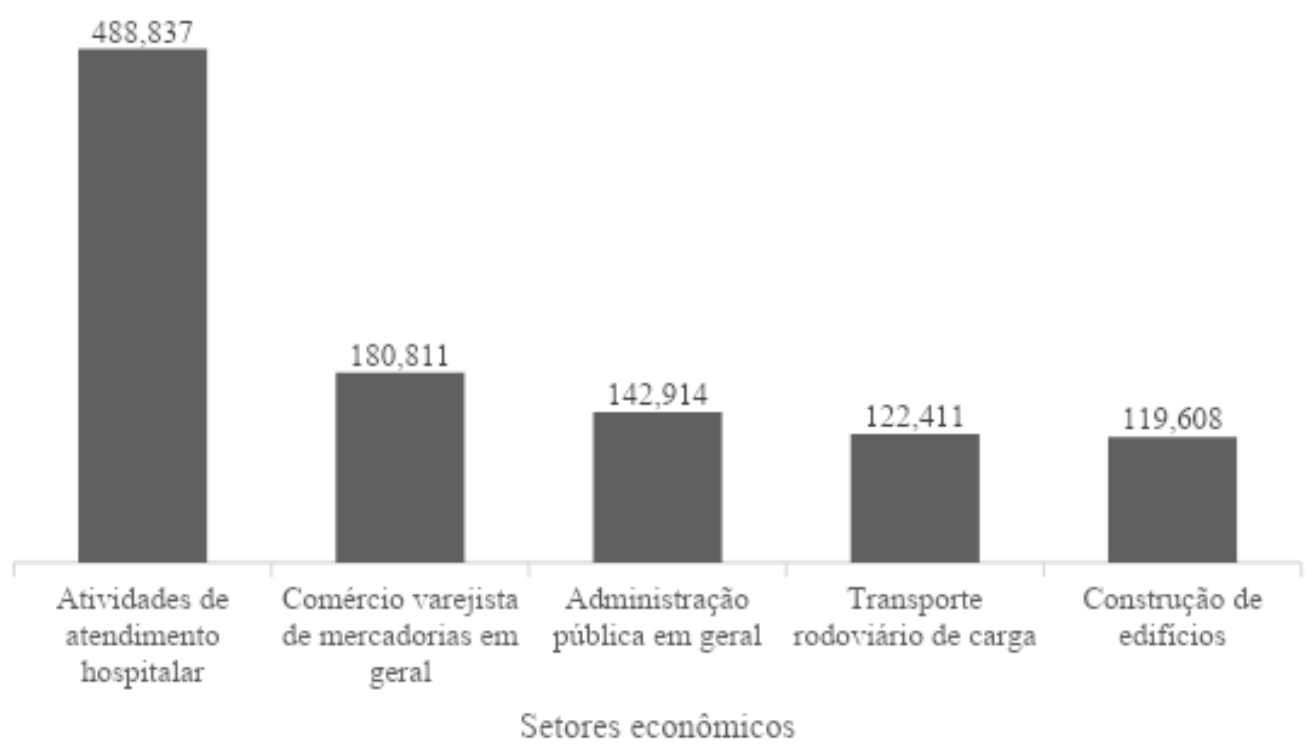

Figura 4: Setores econômicos com maiores índices de acidentes do trabalho de 2012 a 2020.

(Fonte: Adaptado de Observatório Digital de Saúde e Segurança do Trabalho, 2021)

Na Figura 5, são discriminadas as categorias do setor da construção civil onde mais ocorrem acidentes, de acordo com dados coletados entre os anos de 2012 e 2020. Assim, é possível observar que a construção de edifícios possui maior representatividade no que tange ao número de acidentes do trabalho. Por conseguinte, a incorporação imobiliária, a construção de rodovias e ferrovias, as obras de terraplenagem e as obras de urbanização. 


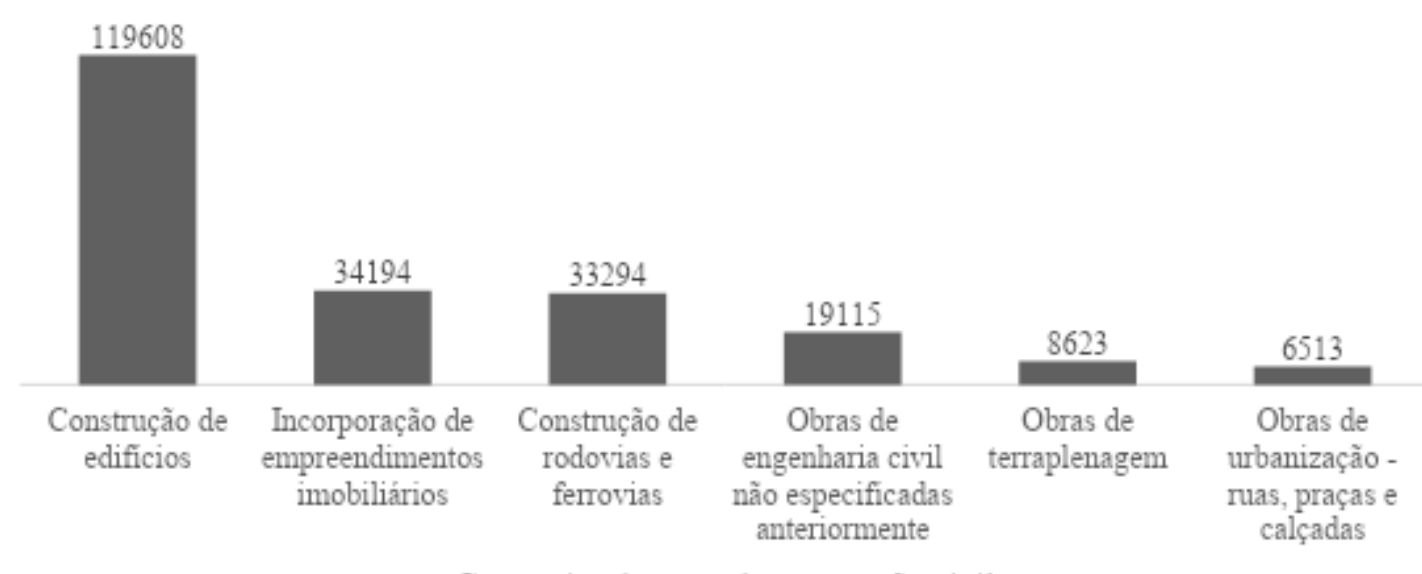

Categorias do setor da construção civil

Figura 5: Acidentes de trabalho da categoria de construção civil de 2012 a 2020. (Fonte: Adaptado de Observatório Digital de Saúde e Segurança do Trabalho, 2021)

Ao analisar os tipos de ocupação do setor da construção civil que mais têm acidentes notificados, verifica-se que a ocupação de servente de obras é responsável por cerca de $38 \%$ dos acidentes (Figura 6). Os serventes pertencem ao segmento que tem os menores salários entre todos os da indústria da construção civil, além do alto índice de rotatividade e realização de trabalho em hora extra (RODRIGUES, 2005). Destacam-se, ainda, as ocupações de soldador e pedreiro com elevados índices de acidentes, e, em última posição, o engenheiro civil.
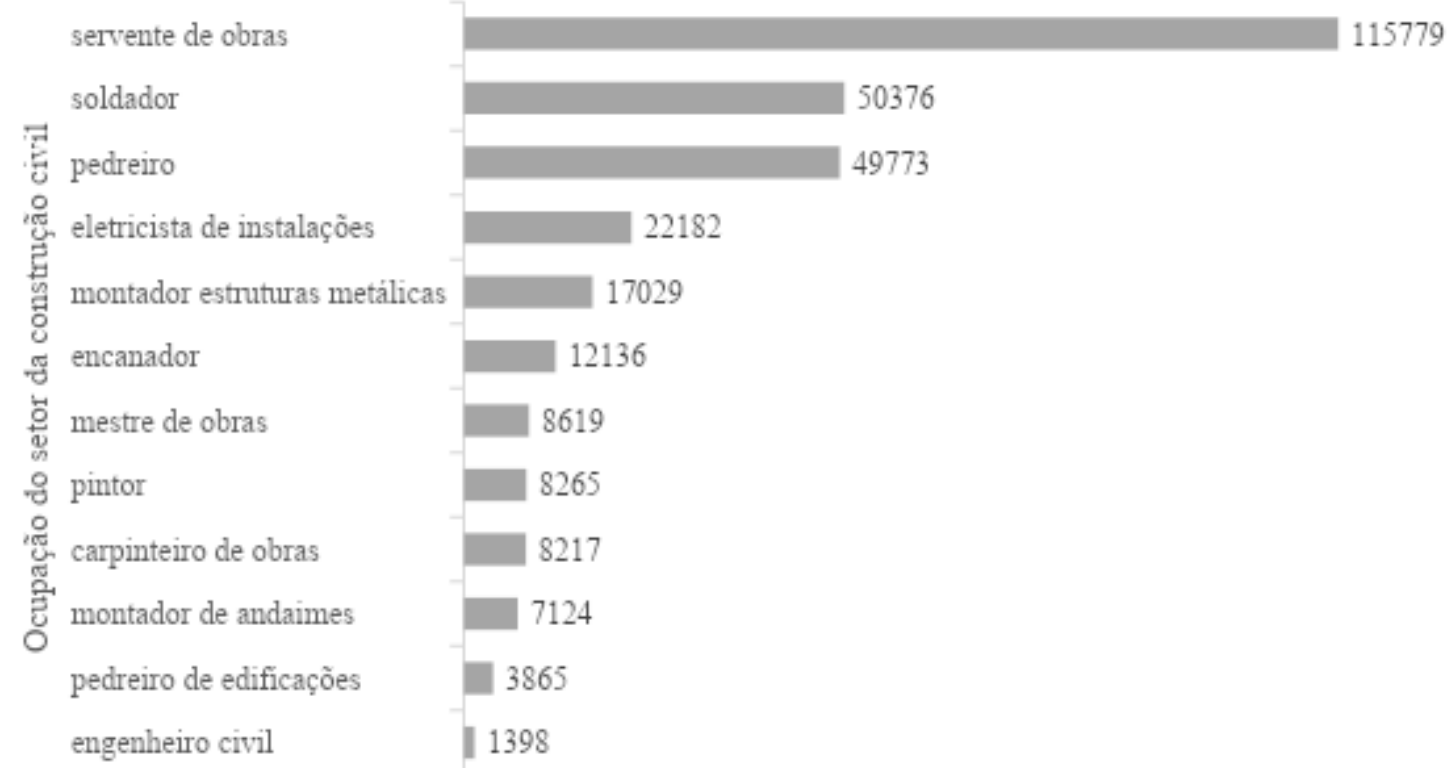

Figura 6: Número de acidentes de trabalho por ocupação (2012-2020) (Fonte: Adaptado de Observatório de Segurança e Saúde no Trabalho, 2021) 
Diante desse cenário, é possível afirmar que os números apresentados nas Figuras 4, 5 e 6 são consequência da falta de investimento em segurança do trabalho no setor da construção civil, fruto da baixa incorporação de uma cultura de segurança nas empresas.

Uma importante estratégia para a implantação de uma cultura prevencionista é a conscientização do trabalhador. Os profissionais da Segurança são os responsáveis pela conscientização dos trabalhadores em relação ao adequado uso de EPIs, assim como pela elaboração e execução do PGR (Programa de Gerenciamento de Riscos) e a implantação de medidas de proteção coletiva. Isso pode ser operacionalizado por meio de palestras, treinamentos, cursos de segurança e incentivos, os quais são fatores determinantes para que a obra seja realizada de maneira eficaz e segura (SAMPAIO, 2020).

É importante que todos os grupos hierárquicos de uma empresa tenham conhecimento acerca da segurança, para que haja o desenvolvimento e a implementação de ações eficazes com vistas a mitigar os riscos no local de trabalho (MARÍN et al., 2019).

c. Cumprimento das normas regulamentadoras no setor da construção civil

Uma pesquisa realizada pela Câmara Brasileira da Indústria da Construção, no ano de 2018, indicou os quantitativos de empresas de construção civil existentes no Brasil (Tabela 2). Observa-se que a maioria dessas empresas são as microempresas $(91,31 \%)$ e as de pequeno porte $(7,32 \%)$.

Costella et al. (2014) realizaram uma pesquisa em 115 canteiros de obras de pequeno, médio e grande portes em que se procurou avaliar o cumprimento da NR-18 nas obras de construção civil nesses canteiros (Tabela 3). Pode-se constatar que as obras de grande porte são as que mais atendem aos itens da NR-18 (média de 64,7\% dos itens), enquanto as obras de médio porte cumpriram $45,6 \%$ das determinações e as de pequeno porte, apenas $19,7 \%$ dos itens. Tabela 2: Quantitativo das empresas de construção civil por porte no Brasil em 2018. Fonte:

CBIC, 2020.

\begin{tabular}{ccc}
\hline Porte da empresa & Unidades & Porcentagem \\
\hline Micro & 180.490 & 91,31 \\
Pequeno & 14.465 & 7,32 \\
Médio & 2.359 & 1,19 \\
Grande & 353 & 0,18 \\
\hline
\end{tabular}

Costella et al. (2014) realizaram uma pesquisa em 115 canteiros de obras de pequeno, médio e grande portes em que se procurou avaliar o cumprimento da NR-18 nas obras de construção civil nesses canteiros (Tabela 3). Pode-se constatar que as obras de grande porte são as que mais atendem aos itens da NR-18 (média de 64,7\% dos itens), enquanto as obras de médio porte cumpriram $45,6 \%$ das determinações e as de pequeno porte, apenas $19,7 \%$ dos itens.

Tabela 3: Porcentagem do cumprimento da NR-18 por empresas de pequeno, médio e grande portes. Fonte: Costella et al., 2014.

Persp. Online: exatas \& eng., Campos dos Goytacazes, 33(11) 19-33-2021

https://ojs3.perspectivasonline.com.br/ 
Porte da empresa
Cumprimento da NR 18

$19,70 \%$

$45,60 \%$

$64,70 \%$

Embora seja esperado que as obras de maior porte tenham maior comprometimento com a segurança e a saúde do trabalhador, pode-se notar que ainda há muito a ser melhorado mesmo nessas empresas, uma vez que, em média, 35,3\% dos itens da NR-18 avaliados nessas obras não foram atendidos. Além disso, supondo que a referida pesquisa fosse expandida para as demais normas regulamentadoras que se aplicam à construção civil, o percentual de requisitos de segurança e saúde do trabalho não atendidos aumentaria.

Relacionando os dados da Tabela 2 com os da Tabela 3 (Figura 7), constata-se que a maioria das empresas do Brasil são justamente as que menos cumprem a NR-18, e, possivelmente, as demais normas regulamentadoras referentes ao setor da construção civil.

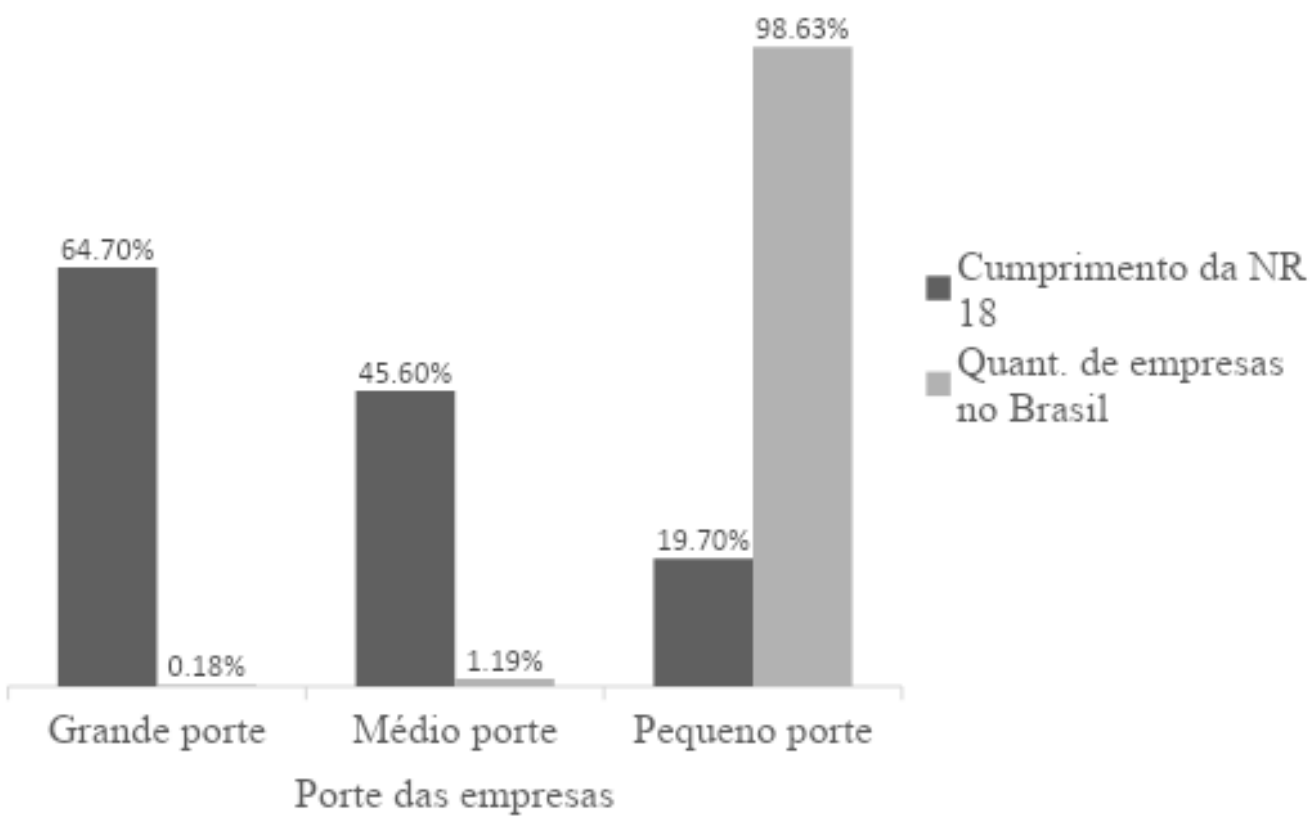

Figura 7: Comparação de dados de empresas de pequeno, médio e grande portes. (Fonte:

Autores, 2021)

Diante do contexto apresentado, pode-se inferir que o predomínio de empresas de pequeno porte no setor da construção civil no Brasil contribui potencialmente para o alto índice de acidentes nesse setor, já que essa classe de empresas representa a que menos atende às normas regulamentadoras de segurança do trabalho.

É importante destacar que quando a empresa responsável pela obra preza pelo cumprimento das normas regulamentadoras, consequentemente é exigido o mesmo de seus 
terceirizados, pois, além de ser uma obrigação legal, é uma forma de proteção da reputação da organização. Assim, as ações das empresas têm a capacidade de influenciar positivamente outras no cumprimento das normas.

d. Investimentos em segurança do trabalho em empresas de construção civil

Muitas empresas apresentam resistência em investir em segurança, principalmente por acreditarem que, se optarem por cumprir as normas regulamentadoras, podem comprometer sua receita. No entanto, essa maneira de pensar está equivocada, uma vez que os custos provenientes dos acidentes de trabalho são mais onerosos em comparação aos custos de se investir em uma cultura organizacional de segurança (WELTER, 2014).

É importante salientar que a resistência das empresas em investir em segurança impacta os órgãos públicos, uma vez que, em casos de acidentes de trabalho, cabe ao Instituto Nacional do Seguro Social (INSS) administrar a prestação de benefícios, tais como auxílio-doença acidentário, auxílio-acidente, habitação e reabilitação profissional e pessoal, aposentadoria por invalidez e pensão por morte (GIZONI e MARCO, 2018).

Segundo dados do Observatório de Segurança e Saúde no Trabalho (2021), no ano de 2020, foram gastos 1,7 bilhão com auxílio-doença, 5,4 bilhões com aposentadoria por invalidez por acidente do trabalho, 2,3 bilhões com pensão por morte por acidente do trabalho, 4,3 bilhões com auxílio-acidente por acidente do trabalho, entre outros (Figura 8).

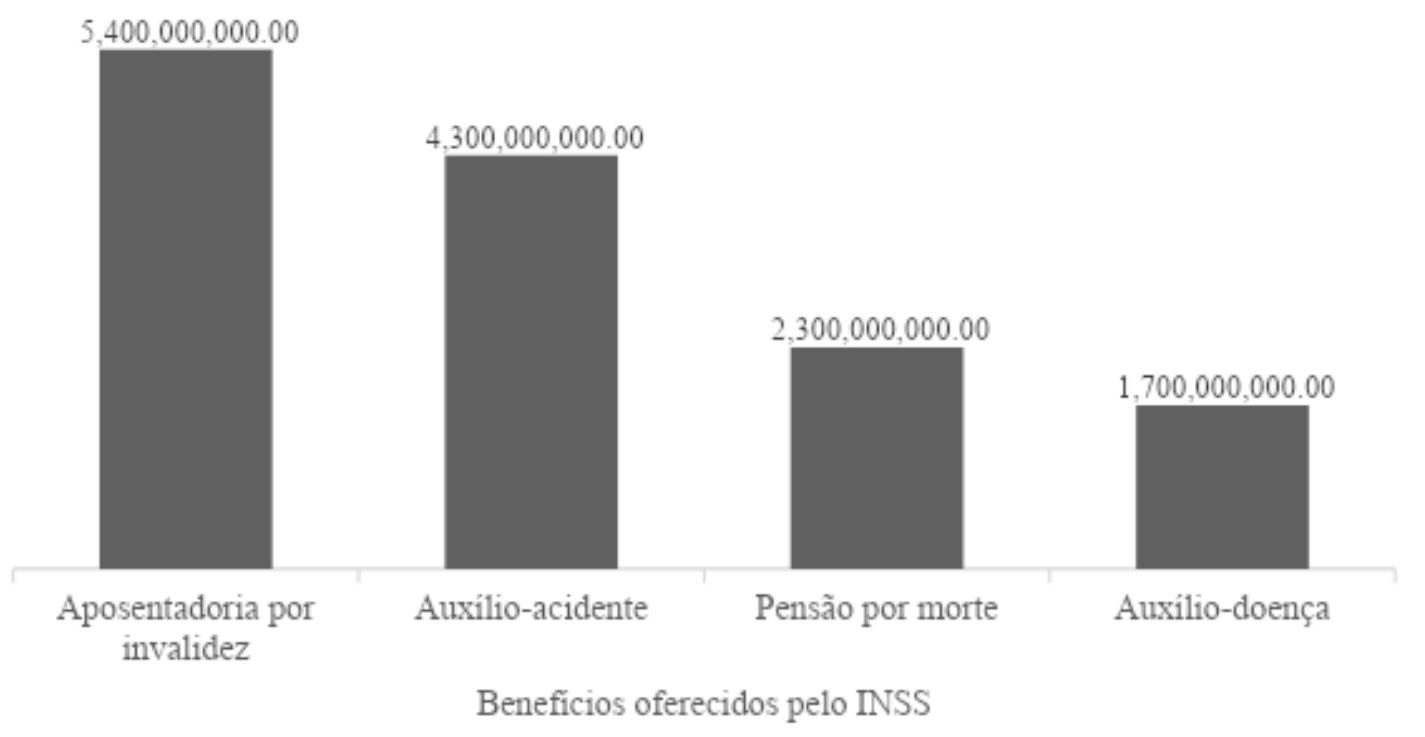

Figura 8: Gastos públicos provenientes de acidentes do traballho no ano de 2020 (Fonte: Observatório de Segurança e Saúde no Trabalho, 2021)

A grande soma de recursos públicos gastos em virtude das consequências dos acidentes de trabalho evidencia a dimensão do prejuízo que a falta de investimentos em segurança traz ao país. 
A maioria das empresas não visualiza os custos indiretos relacionados a acidentes do trabalho, e estes custos podem ser de três a dez vezes maiores que os custos diretos. Welter (2014) faz uma comparação entre os custos da segurança e da não segurança em empresas da construção civil, em que ficam evidenciados os custos indiretos associados (Tabela 4). Todo acidente ocorrido, por mais simples que seja, desencadeia uma série de despesas que em sua maioria não são claramente percebidas pela empresa. Essa falta de conhecimento pode ser considerada um fator contribuinte para a negligência da segurança do trabalho, portanto, é importante haver essa conscientização dos custos indiretos associados aos acidentes (WELTER, 2014).

Tabela 4: Diferenças de custos da não segurança e da segurança. Fonte: Adaptado de WELTER (2014)

\begin{tabular}{|c|c|}
\hline Custos da Não segurança & Custos da segurança \\
\hline Custos do transporte e atendimento médico; & $\begin{array}{l}\text { Tempo dos trabalhadores utilizado durante as } \\
\text { atividades de treinamento; }\end{array}$ \\
\hline $\begin{array}{l}\text { Pagamento de benefícios e indenizações aos } \\
\text { acidentados e suas famílias; }\end{array}$ & $\begin{array}{l}\text { Custos dos treinamentos, conscientização e } \\
\text { capacitação dos trabalhadores; }\end{array}$ \\
\hline Pagamento de multa e penalizações; & $\begin{array}{l}\text { Custos com exames médicos de } \\
\text { monitoramento de saúde; }\end{array}$ \\
\hline $\begin{array}{l}\text { Tratamento de pendências jurídicas, tais como } \\
\text { processos criminais por lesões corporais, } \\
\text { indenizatórias e previdenciárias; }\end{array}$ & $\begin{array}{l}\text { Manutenção de equipes de SST e respectivos } \\
\text { encargos sociais; }\end{array}$ \\
\hline $\begin{array}{l}\text { Tempo não trabalhado pelo acidentado durante } \\
\text { o atendimento e o período em que fica } \\
\text { afastado; }\end{array}$ & $\begin{array}{l}\text { Aquisição de equipamento de proteção } \\
\text { individual; }\end{array}$ \\
\hline $\begin{array}{l}\text { Tempo despendido pelos supervisores, equipes } \\
\text { de SST e médica durante o atendimento; }\end{array}$ & $\begin{array}{l}\text { Tempo para desenvolvimento de projetos e } \\
\text { instalação de proteções coletivas; }\end{array}$ \\
\hline $\begin{array}{l}\text { Baixa moral dos trabalhadores, perda de } \\
\text { motivação e consequente queda de } \\
\text { produtividade; }\end{array}$ & Placas de identificação e orientativas de SST; \\
\hline $\begin{array}{l}\text { Tempo de paralisação das atividades pelo } \\
\text { poder público e consequente prejuízo à } \\
\text { produção; }\end{array}$ & $\begin{array}{l}\text { Manutenção da infraestrutura nos canteiros } \\
\text { (áreas de vivência, refeitórios, alojamento, } \\
\text { sanitários); }\end{array}$ \\
\hline $\begin{array}{l}\text { Tempo para a limpeza e recuperação da área e } \\
\text { reinício das atividades; } \\
\text { Tempo dos supervisores para investigar os } \\
\text { acidentes, preparar relatórios e prestar } \\
\text { esclarecimentos às partes interessadas: clientes, } \\
\text { sindicatos, imprensa etc.; }\end{array}$ & $\begin{array}{l}\text { Custos com realização de medições de } \\
\text { condições ambientais (ruído, iluminação, } \\
\text { vapores etc.). }\end{array}$ \\
\hline
\end{tabular}


Tempo de recrutamento e capacitação de um novo funcionário na função do acidentado, durante o seu afastamento.

Os treinamentos de segurança, a conscientização e capacitação dos trabalhadores são importantes para o fortalecimento das estratégias de mitigação dos riscos de acidentes. Deve-se destacar, também, o papel dos avanços tecnológicos aplicáveis à construção civil, os quais oferecem diversos recursos que podem ser implementados a fim de promover a segurança, como, por exemplo: Tecnologias de Informação e Comunicação (TIC); Modelagem da Informação da Construção (BIM); realidade virtual e aumentada. Tais tecnologias contribuem para componentes tecnológicos (hardware, software, rede, base de dados e serviços) que oferecem suporte para os sistemas de informação da empresa (PEINADO, 2019).

Nota-se que no Brasil há ainda um longo caminho a ser trilhado até que haja verdadeiramente uma cultura empresarial voltada para a segurança, como se pôde perceber pelas pesquisas apresentadas. Faz-se necessário compreender que a segurança laboral gera um ambiente organizado, que, por sua vez, tem relação direta com a produtividade da empresa, trazendo, assim, benefícios aos empregados e aos empregadores.

\section{CONCLUSÕES}

A partir dos resultados das pesquisas apresentadas, verifica-se que o setor da construção civil é caracterizado por um alto índice de informalidade de seus trabalhadores, possui um alto nível de taxa de rotatividade em relação aos demais setores econômicos nacionais, e é o quinto setor com maior número de acidentes de trabalho no país, sendo que, dentre as categorias e os tipos de ocupação do setor da construção civil, os que mais causam acidentes do trabalho são, respectivamente, a construção de edifícios e a ocupação de servente de obras.

Identificou-se, também, que a maioria das empresas brasileiras de construção civil não cumpre com a NR-18, e, possivelmente, com as demais normas regulamentadoras aplicáveis ao setor, e que há pouco investimento em segurança do trabalho nas organizações, o que acarreta maiores gastos, tanto para as empresas quanto para os órgãos públicos, visto que os custos da não segurança se mostram maiores do que os custos da segurança.

Os fatores apresentados contribuem para o elevado número de acidentes do trabalho na construção civil. Desse modo, verifica-se a necessidade de investimento por parte das empresas em uma cultura de segurança, a qual implica a observância das normas regulamentadoras, o engajamento de todos os níveis hierárquicos da organização com relação à segurança do trabalho, visto que tal compromisso contribui para um clima organizacional que influencia na qualidade e segurança do ambiente laboral, e a implementação de inovações tecnológicas aplicáveis ao setor, as quais podem contribuir com a eficácia no atendimento às normas.

Sabe-se que mesmo que se atenda a todas as medidas previstas de segurança, não se pode erradicar por completo os riscos, mas sim, mitigá-los. Portanto, quando se implementam ações voltadas para a conscientização dos riscos existentes, os cuidados que devem ser tomados e as normas a serem seguidas, todo o ambiente de trabalho se torna mais seguro e 
isso afeta positivamente não somente os funcionários, mas a empresa como um todo, contribuindo para a redução dos índices de acidentes.

Espera-se que o presente artigo possa contribuir com a pesquisa acadêmica nesta temática, bem como mobilizar os órgãos e empresas do ramo para a problemática aqui abordada.

\section{REFERÊNCIAS}

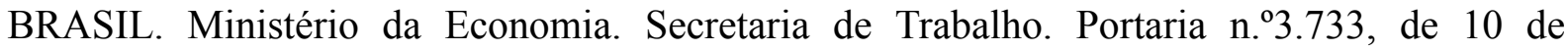
fevereiro de 2020. NR 20, Norma Regulamentadora-20 (2020) Condições de Segurança e Saúde no Trabalho na Indústria da Construção. Diário Oficial da União, Poder Executivo, Brasília, DF, 11 fev. 2020.

CASAGRANDE, L. E. M. Avaliação da cultura de segurança na construção civil: um estudo de caso. 2017. 53p. Monografia (Curso de especialização) - Universidade Tecnológica Federal do Paraná - Londrina, PR.

CBIC. Câmara Brasileira da Indústria da Construção. Economia nacional e construção civil: desempenho recente e perspectivas. Brasil, 2020. Internet. Disponível em: < https://cbic.org.br/wp-content/uploads/2020/02/ieda.pdf>. Acesso em 24 abr. 2021.

CELERE. Como reter talentos na construção civil. Brasil, maio de 2019. Internet. Disponível em: < https://celere-ce.com.br/gestao/como-reter-talentos-na-construcao-civil/> . Acesso em: 07 abr. 2021.

COSTELLA et al. Avaliação do cumprimento da NR-18 em função do porte de obra residencial e proposta de lista de verificação da NR-18. Ambiente Construído, Porto Alegre, v. 14, n. 3, p. 87-102, jul./set. 2014.

FILGUEIRAS, V. A. et al. Saúde e Segurança do Trabalho na Construção Civil Brasileira. Aracaju: J.Andrade, 2015

GIZONI, M. S.; MARCO, G. A Importância da Segurança no Trabalho na Construção Civil: um estudo no município de Jaboticabal - SP. 2018. 21p. Monografia (Bacharelado) - UNIARA, Araraquara - SP.

GONÇALVES FILHO, A. P. et al. Cultura e gestão da segurança no trabalho: uma proposta de modelo. Gestão \& Produção, São Carlos, v. 18, n.1, p. 205-220, 2011.

GONÇALVES, F.A. Segurança do Trabalho na Construção Civil: Análise da segurança nos trabalhos em altura. 2018. 56p. Monografia (Bacharelado) - Universidade Federal de Ouro Preto.

MARÍN, L. S. et al. Percepções do clima de segurança entre o pessoal da construção: associações com taxas de lesões. Ciência da Segurança, v. 118, p. 487-496, out. 2019 
MENDES, R.; CAMPOS, A. C. C. Saúde e Segurança no Trabalho Informal: desafios e oportunidades para a indústria brasileira. Revista Brasileira de Medicina do Trabalho, Belo Horizonte, v. 2, n. 3, p. 209-223, jul./set. 2004.

OBSERVATÓRIO DE SEGURANÇA E SAÚDE NO TRABALHO. Brasil, 2021. Internet. Disponível em: < https://smartlabbr.org/sst/>. Acesso em: 29 maio 2021.

OLIVEIRA, R. P.; IRIART, J. A. B. Representações do trabalho entre trabalhadores informais da construção civil. Psicologia em estudo, Maringá, v.13, n.3, p. 437-445, jul./set. 2008.

PEINADO, H. S. Segurança e Saúde do Trabalho na Indústria da Construção Civil. São Carlos: Editora Scienza, 2019.

RODRIGUES, P. F. V. Um estudo com trabalhadores acidentados da indústria da construção civil do município de Porto Alegre (RS). Dissertação (mestrado). Instituto de Filosofia e Ciências Humanas. Universidade Federal do Rio Grande do Sul, 2005.

SAMPAIO, A. T. et al. Segurança do trabalho e medidas de proteção na construção civil. Brazilian Journal of Development, v.6, n.3, p.9983-9997, 2020.

SCOPUS Elsevier. What is SCOPUS. Disponível em: $<$ https://www.scopus.ez81.periodicos.capes.gov.br/search/form.uri?display=basic\#basic > Acesso em: 19 jun. 2021.

WELTER, L. B. Segurança do Trabalho na Construção Civil: Análise da segurança nos trabalhos em altura. 2014. 63p. Monografia (Curso de especialização) - Departamento de Ciências Exatas e Engenharias - Universidade Regional do Noroeste do Estado do Rio Grande do Sul - Ijuí, RS. 